\title{
Large-scale project system management based on Hall three-dimensional structure
}

\author{
Zhang Rui \\ Tan Kah Kee College Xiamen University, Zhangzhou China \\ 151454126@qq.com
}

Keywords: project management; systems engineering; Hall three-dimensional structure

\begin{abstract}
Nowadays project management has been deeply rooted in various fields and places of society. It plays an important role in social life. The large project management with a large-scale and costly, involving broad, longer study period and other characteristics. The application of systematic methods to manage it is an inevitable trend in the development of project management. Hall three-dimensional structure is a typical methodology of system engineering. This paper applies its application for large project to a systematic description of large projects. On the base, the project management activity matrix is proposed to form a new management method.
\end{abstract}

\section{Introduction}

In today's society, all walks of life in society are inseparable from projects. Projects are everywhere. This puts forward higher requirements for project management. How to manage the project is the key to the success of the project, especially the large-scale projects. Large-scale projects have the characteristics of large scale, huge cost, extensive content, and long research period. They are a kind of complex system engineering. They are usually composed of several subsystems, and are collaboratively completed by numerous units. This puts higher requirements on the management capabilities of large-scale projects. To manage large projects, it requires that its management must continue to innovate.

The continuous innovation of management requires the continuous improvement in management capabilities. Due to the characteristics of large-scale projects, their management capabilities are reflected their on engineering capabilities. The ability to organize and manage large-scale systems, the so-called "system engineering capabilities", has become a key factor of the success of large-scale projects. The core of large-scale project system engineering capability is the ability to integrate project-oriented resources and achieve rapid and effective integration to achieve project goals. In today's changing era, the rapid and effective integration of projects is ensured by system engineering supporting the environment.

\section{Hall three-dimensional structure}

Hall three-dimensional structure, also known as Hall's system engineering, is a system engineering methodology proposed by the US system engineering expert Hall in 1969. Its appearance has provided a unified way of thinking for solving the problems of planning, organization and management of large-scale and complex systems, and it has been widely used in various countries of the world.

Hall three-dimensional structure divides the whole process of system engineering into seven stages and seven steps, at the same time also considers the various professional knowledge and skills needed to complete these stages and steps. In this way, a three-dimensional space structure composed of a time dimension, a logical dimension, and a knowledge dimension is formed, as shown in figure1. 


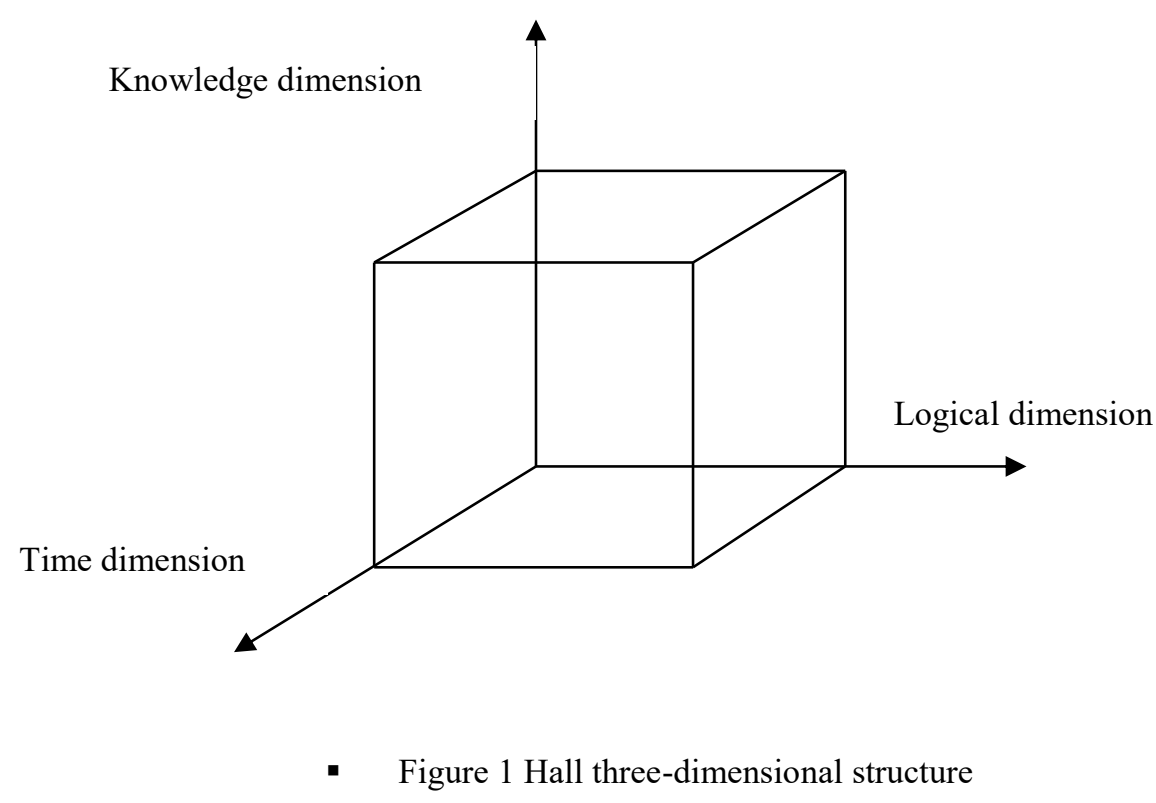

\section{1 time dimension}

It represents the whole process of the system engineering activities from the beginning of the end to chronological order. It is divided into seven phases: planning, drafting plans, research and development, production, installation, operation and updating.

\section{2 logical dimension}

It refers to the content of the work to be carried out in each phase of the time dimension and the thinking procedures that should be followed, including clear issues, target determination, system integration, and system analysis. Optimize, make decisions, and implement seven logical steps.

\section{3 knowledge dimension}

List the various knowledge and skills that need to be applied including engineering, medicine, architecture, business, law, management, social science, art, and so on. The three-dimensional structure system graphically describes the framework of system engineering research. It can be further developed on any stage and every step, and a hierarchical tree system is formed. The structure has a holistic approach to research methods (three-dimensional), comprehensive application of technology (knowledge dimension), scientific (time dimension and logic dimension) of organizational management, and guidance (logical dimension) of system work issues. It is a systematic engineering methodology that solves large-scale project management problems with large scale, complex structure and many factors.

This paper attempts to apply Hall three-dimensional structure in system engineering to the large-scale project management systematic management. According to the characteristics of project systemization, the project management activity matrix is proposed to form a new type of management method.

\section{Project management system description}

According to system theory, project management has the characteristics of a general system: integration, relevance, purpose, environmental adaptability, openness, and so on. Therefore, a successful project must have a comprehensive system management, which requires the application of system engineering methods and thinking to optimize. Any project is a complex system whose complexity is reflected on many aspects such as objects, goals and behaviors.

\subsection{Project management system object}

The project is a combination of many parts and functions. It has its own system structure. They are related to each other, influence each other, and depend on each other to form the project system. 
The object of the project system determines the type and nature of the project, determines the basic image and the most essential characteristics of the project, and determines various aspects of project implementation and project management.

\subsection{Project Management System Target}

The goal of the project management system is the result of the project's behavior, which is the sum of the final states it strives for. Project management system objectives have the following characteristics: First, it has its own complete structure, any system goals can be decomposed into sub-objects according to the system's objects, sub-goals can be decomposed by system behavior, so that the overall goal is gradually refined. The implementation phase is gradually realized. Then, the balance of goals, the project needs to pay special attention to the balance between progress, cost and quality, and one-sided emphasis on a certain goal, often at the expense of sacrificing or damaging another goal. Finally, clarification and dynamics of the objectives. Each goal in the target system must be specified in the plan. At the same time, the goal has a dynamic development process. Changes in the objectives are reflected on changes in the design plan and contract changes, implementation of adjustments and other aspects of the program.

\subsection{Project management system behavior}

Project management is the necessary behavior of the worm to achieve the goal, and through a variety of activities, solve the problem, accomplish the above task and achieve the goal. The behavior of project management system includes the main means of realizing the project target system. Guarantee the project implementation processes sequence, rationalization, balanced use of resources, reduce the uneven cross, maintain order; To ensure the implementation of each part and to achieve a favorable and reasonable coordination between each major The behavior of the project management system has a certain degree of abstraction and is represented by the project structure diagram, network, implementation plan, and resource plan.

\section{Large-scale project system management}

Based on the description of the project management system, this paper discusses the application of Hall three-dimensional structure of the system engineering to manage the implementation of large-scale projects. The ideas are as follows:

\subsection{Establish the system's target system}

A successful project needs in cost, quality and progress of three aspects to achieve the optimal at the same time. On the basis of combining the goal of system requirements, set up the goal of the system.

\subsubsection{Cost}

The cost of the project directly affects the profitability of the project. It is a major indicator of the system and requires management and control from various aspects. According to the behavior of the project, the objectives of cost management are categorized into: valuation, budget estimation and budget; cost to plan; payment plan; cost control, including examination and supervision cost expenditure, cost tracking and diagnosis; settlement audit and cost accounting.

\subsubsection{Quality}

Comprehensively reflects the project organization and work performance. The goal of quality control is to ensure that the design intent is achieved in accordance with the requirements of the contract and related standards, so that the quality objectives of the project can be achieved. According to the object of management of the project, the objectives of quality control are further clarified as follows: ensure that the project meets the requirements and standards, and is equivalent to the cost, provide an independent and fair evaluation system for the project manager's management quality, timely discover and correct the project during the implementation process Quality problems arise, master relevant information of the project. 


\subsubsection{Progress}

Progress control is for the whole process of project management. Through planning, organizing, coordinating, checking and scheduling, etc. all positive factors are mobilized and efforts are made to achieve the objectives of each stage of the project management process, so as to ensure that progress goals are achieved. According to the project management object, the goals of schedule control can be detailed as follows: to prepare the schedule plan; Track and check progress on schedule: analyze and adjust progress.

\subsection{Establish a project management system activity matrix}

There are three dimensions in a Hall three-dimensional structure model, and three-dimensional structure can constitute a spatial structure diagram. In order to be visual and intuitive, the three-dimensional structure diagram can be simplified as a plan view. According to the specific implementation process and target system of the project management system, combined with Hall three-dimensional structure method, a project management system activity matrix table is established.

The content of logic dimension and time dimension in Hall's three-dimensional structure is mainly determined by the system object and system behavior. The system object corresponds to the specific activity determined in the time dimension. The system behavior corresponds to each step in the logical dimension. For the project system, its time dimension combined with the project implementation process is divided into four phases: project phase, design phase, implementation phase, and end phase. The logical dimension is based on the effective behavior of the project implementation, namely: forecasting, decision making, planning, control and feedback. In this way, the time dimension and logic dimension in Hall three-dimensional structure can form a $4 \times 5$ project system activity matrix table. As shown in Table 1, each element in the table represents an activity.

Table 1. Project Management System Activity Matrix

\begin{tabular}{c|c|c|c|c|c}
\hline $\begin{array}{c}\text { Time/Logical } \\
\text { Dimensions }\end{array}$ & Prediction & Decision & Plan & Control & Feedback \\
\hline Project Phase & $\mathrm{A}_{11}$ & $\mathrm{~A}_{12}$ & $\mathrm{~A}_{13}$ & $\mathrm{~A}_{14}$ & $\mathrm{~A}_{15}$ \\
\hline Design stage & $\mathrm{A}_{21}$ & $\mathrm{~A}_{22}$ & $\mathrm{~A}_{23}$ & $\mathrm{~A}_{24}$ & $\mathrm{~A}_{25}$ \\
\hline Implementation Phase & $\mathrm{A}_{31}$ & $\mathrm{~A}_{32}$ & $\mathrm{~A}_{33}$ & $\mathrm{~A}_{34}$ & $\mathrm{~A}_{35}$ \\
\hline The closing stage & $\mathrm{A}_{41}$ & $\mathrm{~A}_{42}$ & $\mathrm{~A}_{43}$ & $\mathrm{~A}_{44}$ & $\mathrm{~A}_{45}$ \\
\hline
\end{tabular}

\subsection{Determine the main task for each activity.}

Analyze the project management system activity matrix to determine the main tasks for each activity.

4.3.1 Project stage

$\mathrm{A}_{11}$ : By obtaining the relevant project materials, it is predicted from the development of the company's strategy to bid for the risk of contracting the project.

$\mathrm{A}_{12}$ : Make decisions based on the intention of the project stakeholders, the actual situation on the site, the characteristics of competitors, and the market conditions of resources.

$\mathrm{A}_{13}$ : Analyze the relevant data obtained from the analysis and conduct project risk analysis and project valuation.

$\mathrm{A}_{14}$ : According to the project risk analysis and project valuation, make a reasonable bid strategy and determine the quotation.

$\mathrm{A}_{15}$ : Feedback some of the information found during the bidding process of the bidding process of comprehensive analysis.

4.3.2 Design stage:

$\mathrm{A}_{21}$ : Establish a project team to identify project team members. Conduct survey and preliminary planning of project design.

$\mathrm{A}_{22}$ : Further study the relevant documents of the contract and implement the investigation, and determine the specific project management plan. 
$\mathrm{A}_{23}$ : Prepare a summary of project work, conduct work decomposition of the project as a whole, and implement the work breakdown responsibility. Formulate implementation plan, schedule, cost to plan, and production factor acquisition plan.

$\mathrm{A}_{24}$ : Ensure the smooth implementation and realization of the plan.

$\mathrm{A}_{25}$ : Feedback the actual survey data and the actual progress of the project to the design stage for comprehensive planning.

\subsubsection{Implementation stage}

$\mathrm{A}_{31}$ : According to the plans for the design stage, combined with the progress of the project, predict possible problems with the implementation process.

$\mathrm{A}_{32}$ : Several feasible plans are made in time for emergencies in the implementation process.

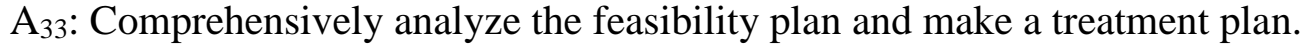

$\mathrm{A}_{34}$ : Under the premise of selecting an appropriate treatment plan, control emergencies can be effectively resolved.

A35: Feedback emergent events to the design plan of the project and make corresponding adjustments.

4.3.4 The end stage

$\mathrm{A}_{41}$ : Problems of the pre-test run at the end of project implementation.

$\mathrm{A}_{42}$ : Accept the inspection.

$\mathrm{A}_{43}$ : Make a financial statement.

A44: Conduct technical and economic analysis and evaluation.

A45: Summary of project management.

\subsection{Analyze the links between various activities in the activity matrix of the project management system}

Analyze the links between activities in the project management system activity matrix table, select coordination factors based on the logical relationship between the activities, and formulate corresponding safeguard measures. Based on the achievement of sub-goals and sub-tasks, the overall goal of project management is achieved through safeguard measures.

\section{Summary}

In many types of projects, due to the characteristics of large-scale projects, the results of the failure of the project are serious, so the goal of the project is higher than the requirements for project management. This article regards large-scale project management as a complex system. It clearly defines the system structure of large-scale project management by analyzing system objectives, system objects, and system behaviors. It considers the overall situation and determines the main tasks of large-scale project management and the main safeguards they perform. It is the system. Theoretical research combined with theory and project management. Using Hall's three-dimensional structure, the general method of large-scale project system management are obtained through modeling analysis, which has both theoretical significance and certain application values. The method can be further enriched and improved on specific applications.

\section{References}

[1] Sun Rongxia, Research on risk of public infrastructure PPP project financing model based on Hall three-dimensional structure, Economic Survey, vol.06, pp. 142-146, 2010.

[2] Su Haihong, and Wang Songjiang, Research on BOT project based on Hall three-dimensional structure, Project Management Technology, vol.07, pp. 26-29,2009.

[3] Fang Wei, Qu Lixiong, and Huang Kexin, Research on Evaluation System of System Engineering Integration Capability of National Defense Major Projects, Future and Development, vol.04 , pp.45-49, 2011. 
[4] Wang Yanwei, and Huang Yi, Integrated management of large-scale complex engineering projects based on three-dimensional structure of PBS and Hall, China Management Information, vol.18, pp.145-146, 2015.

[5] Feng Kailian, Analysis of the reasons for the out-of-control costs of large-scale trilateral projects and their countermeasures-Based on Hall three-dimensional structure model , Building Economics, vol.38,pp.54-57, 2017.

[6] Tian Xiliang, The application research of Hall three-dimensional structure in engineering project excellence, Building Technology Development, vol. 44, pp.75-76, 2017. 